\title{
RECENT JOINT STUDIES RELATED TO THE DEVELOPMENT OF SPACE RADIOISOTOPE POWER SYSTEMS
}

\author{
Daniel P. Kramer ${ }^{(1)}$, Richard Ambrosi ${ }^{(2)}$, Mark Sarsfield ${ }^{(3)}$, Emily Jane Watkinson ${ }^{(2)}$, Ramy Mesalam ${ }^{(2)}$, Hugo \\ Williams ${ }^{(2)}$, Chadwick Barklay ${ }^{(1)}$, Tim Tinsley ${ }^{(3)}$, Steve Goodrich ${ }^{(1)}$, Timothy Pierson ${ }^{(1)}$, Christofer Whiting ${ }^{(1)}$ \\ ${ }^{(1)}$ University of Dayton, Dayton, Ohio,USA,Email:daniel.kramer@udri.udayton.edu \\ ${ }^{(2)}$ University of Leicester, Leicestershire, UK, Email: rma8@leicester.ac.uk \\ ${ }^{3)}$ National Nuclear Laboratory, Sellafield, Cumbria, UK, Email: mark.sarsfield@nnl.co.uk
}

\begin{abstract}
Over the last several years there has been a mutually beneficial ongoing technical interchange between the U.K and the U.S. related to various aspects of space radioisotope power systems (RPS). While this interchange has been primarily focused on materials based activities, it has also included some aspects related to safety, environmental, and lessons learned during the application of RPSs by the U.S. during the last fifty years. Recent joint technical RPS endeavors have centered on the development of a possible "cold" ceramic surrogate for ${ }^{238} \mathrm{PuO}_{2}$ and ${ }^{241} \mathrm{AmO}_{\mathrm{x}}$ and the irradiation of thermoelectrics and other materials at expected RPS related neutron fluences. As the U.S. continues to deploy and Europe develops RPS capability, on-going joint RPS technical interfaces will continue to enhance each entities' endeavors in this nuclear based power technology critical for deep space exploration.
\end{abstract}

\section{BACKGROUND}

Over the last several decades over twenty-five U.S. Radioisotope Power Systems (RPS) have been successfully employed on a number of deep space missions including Galileo (launched 1989 to Jupiter), Ulysses (launched 1990 as a Solar orbital), Cassini (launched 1997 to Saturn), and New Horizons (launched 2006 - fly-by Pluto 2015); and Mars Science Laboratory's rover Curiosity (landed on Mars in 2012).

U.S. RPSs utilize the heat released from the decay of the radioisotope plutonium-238 via thermoelectrics to provide all of the electrical power needed for the spacecraft. Plutonium-238 is employed since it is a strong alpha emitter with a half-life of $\sim 87.7$ years. This provides the needed thermal energy and lifetime which allows the completion of long duration missions.

The employed fuel is an oxide, ${ }^{238} \mathrm{PuO}_{2}$, in the form of a ceramic pellet. The individual pellets are fabricated using various classical ceramic processing operations such as ball milling, screening, and hot pressing. Each pellet is $\sim 150 \mathrm{gms}$ and produces $\sim 62.5 \mathrm{~W}_{\text {th }}$. Current U.S. RPSs utilize a lead telluride based thermoelectric material known as TAGS-85 which converts $\sim 5$ to $6 \%$ of the available thermal energy provided by the radioactive fuel into electricity available for powering a spacecraft.

In Europe over the last several years there has been interest in the development of a European RPS capability for possible future ESA supported space exploratory missions. These efforts are currently based on the application of americium-241 in oxide form as the radioisotope heat source. The radioisotope americium-241 will be separated from used nuclear fuel at the National Nuclear Laboratory in the U.K. ${ }^{241} \mathrm{Am}$ has a half-life of $\sim 432$ years and the RPS fuel would be ${ }^{241} \mathrm{AmO}_{\mathrm{x}}$ also in the form of ceramic pellets likely fabricated again using ceramic processing operations.

By their inherent application of a radioactive fuel, RPSs need to successfully operate in a radiation environment. The total radiation field which the spacecraft and the RPS itself is exposed to will come from the radioactive fuel and, depending on the specific mission profile, the space environment such as is encountered in missions close to Saturn or Jupiter. The current RPS design being investigated at the University of Leicester will utilize bismuth telluride based thermoelectrics to convert some of the decay heat from the ${ }^{241} \mathrm{AmO}_{\mathrm{x}}$ fuel form into electrical power for a spacecraft.

\section{RPS FUEL $\mathrm{CeO}_{2}$ SURROGATE PROCESSING}

\subsection{Cold Press + Sintering Studies}

${ }^{241} \mathrm{AmO}_{\mathrm{x}}$ and ${ }^{238} \mathrm{PuO}_{2}$ are both radioactive making it difficult to readily employ in experiments related to the development and the understanding of how various physical/chemical properties (such as particle size, particle size distribution, etc.) impact their ceramic processing characteristics. Therefore, the application of a non-radioactive surrogate material for performing various endeavours in the U.K. and the U.S. in support of our respective space nuclear power efforts would result in reduced personnel exposure, and additionally in reduced associated costs.

One surrogate material currently under investigation in both the U.K. and the U.S. is cerium dioxide $\left(\mathrm{CeO}_{2}\right)$. Cerium dioxide has a number of chemical and physical 
characteristics which makes it a potentially attractive cold surrogate for ${ }^{241} \mathrm{AmO}_{\mathrm{x}}$ and ${ }^{238} \mathrm{PuO}_{2}$. It can also be processed into pellets utilizing various ceramic processing techniques which can be employed in experiments. One interesting chemical characteristic of the two actinide oxide based fuels are that they may release oxygen atoms under various reducing atmospheres which results in the formation of substoichiometric oxides. This tendency is similar to $\mathrm{CeO}_{2}$ which also tends to release oxygen atoms under various reducing conditions forming sub-oxides with different crystal structures [1-3]. The reduction of $\mathrm{CeO}_{2}$ to $\mathrm{Ce}_{2} \mathrm{O}_{3}$ with hydrogen also has been shown to result in the formation of over thirty intermediate sub-oxide compositions [4].

Several joint U.K./U.S. studies have been performed between the University of Leicester (U of L), National Nuclear Laboratory (NNL), and the University of Dayton (UD) investigating some of the ceramic processing characteristics of $\mathrm{CeO}_{2}$. Experiments have been performed using both commercially available $\mathrm{CeO}_{2}$ powder of different specific particle sizes, and internally (NNL and $\mathrm{U}$ of $\mathrm{L}$ ) produced powder some of which has also been supplied to UD for additional joint investigations.

In one study led by $\mathrm{NNL}, \mathrm{CeO}_{2}$ powder was produced using an "oxalate" technique similar to what is employed in the processing of ${ }^{238} \mathrm{PuO}_{2}$ and likely ${ }^{241} \mathrm{AmO}_{\mathrm{x}}$ powder which typically consists of a precipitation and then the calcination of the precipitate. In this particular study on the chemical preparation of $\mathrm{CeO}_{2}$ powder, two different precipitation temperatures were used followed by one of three different calcination temperatures. Several gram quantities of each of the six powders were also sent to UD where their individual ceramic processing characteristics were studied.

Small ceramic discs have been fabricated at UD using NNL produced $\mathrm{CeO}_{2}$ powders employing standard ceramic cold pressing techniques (hydraulic pressing of $\mathrm{CeO}_{2}$ powder loaded in metal dies). The obtained discs have measured as-pressed green densities which range from $\sim 55 \%$ to $\sim 67 \%$ theoretical density using a $100 \%$ theoretical density for $\mathrm{CeO}_{2}$ of $7.2 \mathrm{gm} / \mathrm{cm}^{3}$. After cold pressing, some of the green discs were next sintered at $1400^{\circ} \mathrm{C}$ for one hour in an air atmosphere furnace. Figure 1 shows an example of one of the sintered $\mathrm{CeO}_{2}$ pellets. After sintering, the theoretical density of the pellets in this study were measured and ranged from $\sim 77 \%$ TD to $\sim 85 \%$ TD. Since plutonium-238 is an alpha emitter, it is desirable to not fully densify the ${ }^{238} \mathrm{PuO}_{2}$ fuel pellets above $\sim 90 \%$ of theoretical density. This facilitates helium removal under various environmental conditions. It is expected that future ${ }^{241} \mathrm{AmO}_{\mathrm{x}}$ pellets will also be fabricated in the same general range of percent theoretical density.

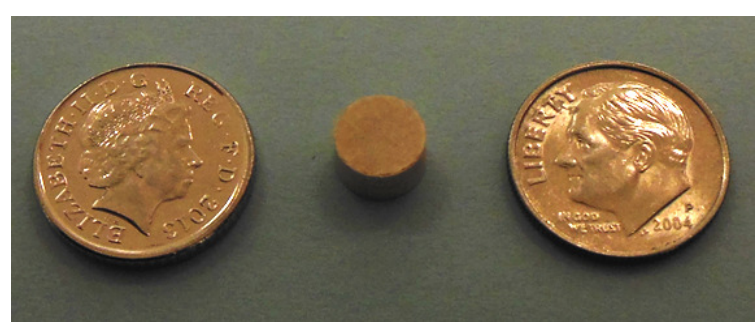

Figure 1. Relative size of a $\mathrm{CeO}_{2}$ pellet sintered at $1400^{\circ} \mathrm{C}$ for one hour.

After sintering, several of the obtained pellets were mounted and polished to examine their microstructures as a function of processing parameters and to obtain microhardness measurements. Figure 2 shows two of the $\sim 0.8 \mathrm{~cm}$ in diameter pellets fabricated in this study after mounting and polishing. The microhardness results showed some differences as a function of precipitation and calcination temperatures as the Vickers Hardness values varied from a mean of $\sim 565$ to $\sim 648$. The hardness values were obtained employing ASTM C1327-08 using a load of 300gms and a dwell time of 15 seconds.

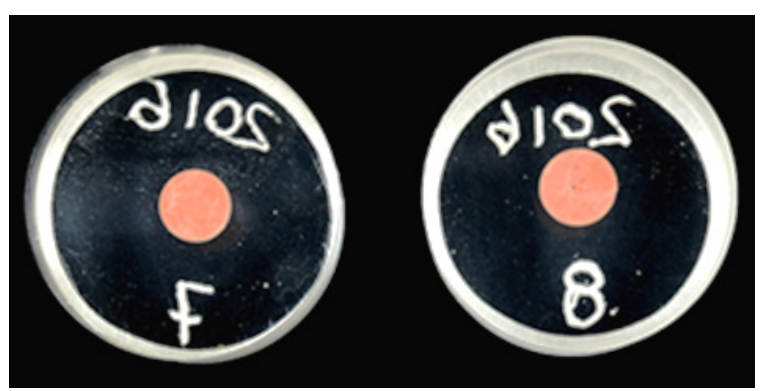

Figure 2. Sintered $\sim 0.8 \mathrm{~cm}$ in diameter $\mathrm{CeO}_{2}$ ceramic discs after mounting and polishing prior to the microhardness tests.

\subsection{Hot Pressing Processing Studies}

In addition to the $\mathrm{CeO}_{2} \mathrm{NNL} / \mathrm{U}$ of $\mathrm{L} / \mathrm{UD}$ processing study discussed above, a number of other ceramic processing studies have been performed using differently processed $\mathrm{CeO}_{2}$ powders and other high temperature ceramic sintering techniques such as spark plasma sintering, and specifically at UD hot pressing which is discussed below.

Hot pressing is one of the ceramic processes currently being employed in the fabrication of ${ }^{238} \mathrm{PuO}_{2}$ fuel pellets. Hot pressing employs temperature + pressure during a specified time-temperature-pressure (t-T-P) cycle and has been used in the fabrication of $\mathrm{CeO}_{2}$ pellets [5]. While hot pressing of ceramic components is generally more complicated compared to cold press + 
sinter, the additional application of pressure can greatly enhance sintering/densification.

Figure 3 is a photograph taken at UD during a $\mathrm{CeO}_{2}$ hot pressing experiment showing the pressure ram (top) while it is applying a load to the top die punch. This hot press utilizes an induction furnace (coil structure in figure) which heats the graphite die which indirectly heats and sinters the $\mathrm{CeO}_{2}$ powder within the die. After the completion of the hot press process during an experiment, the sintered $\mathrm{CeO}_{2}$ pellet was then removed from the die for further investigations.

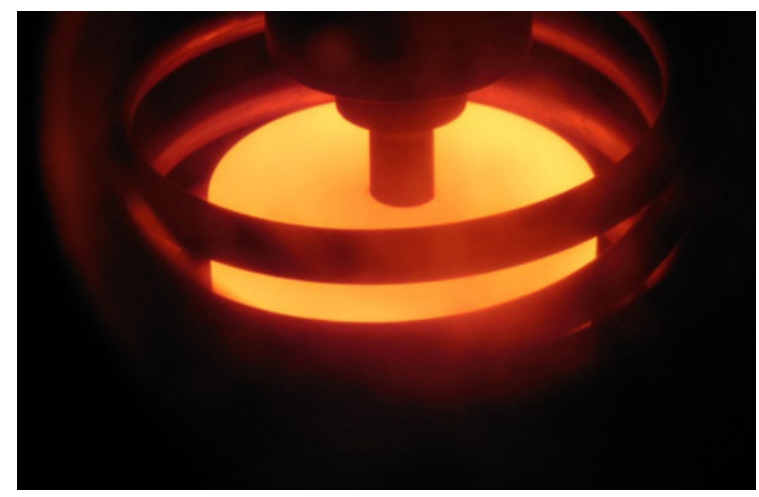

Figure 3. During the hot pressing of a $\mathrm{CeO}_{2}$ pellet.

A number of hot press experiments using various t-T-P processing parameters have been performed in the fabrication of $\mathrm{CeO}_{2}$ hot pressed pellets. Examination of the microstructure of a ceramic pellet can greatly enhance the understanding of the time, temperature, and pressure processing parameters. Several of the obtained $\mathrm{CeO}_{2}$ hot pressed processed pellets have been cut, mounted, and polished for microstructural analysis. One example of an obtained hot pressed $\mathrm{CeO}_{2}$ pellet's microstructure is shown in Figure 4.

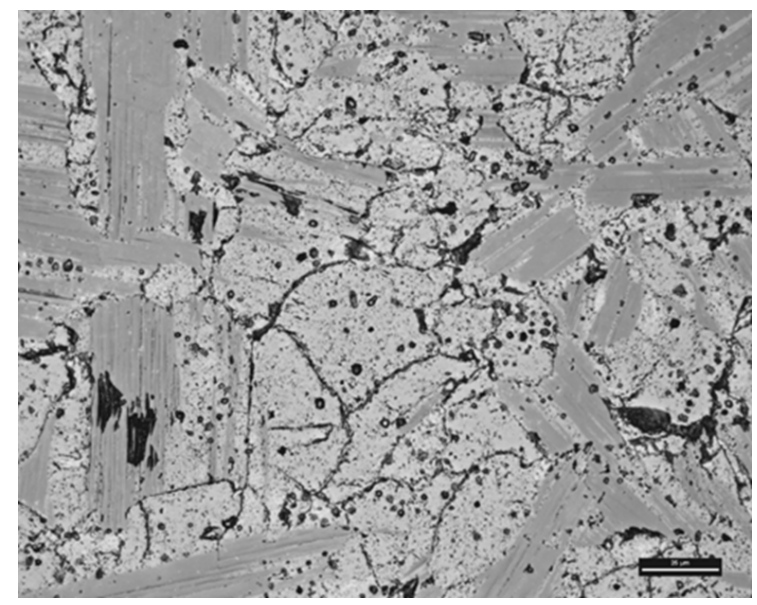

Figure 4. Example of a hot pressed $\mathrm{CeO}_{2}$ pellet microstructure.
The hot pressed $\mathrm{CeO}_{2}$ pellet microstructure shown in Figure 4 exhibits three distinct phases. The black areas are porosity which is desirable in RPS fuel pellets. The other two phases, one columnar and one nodular, have previously been determined to be different general suboxides of $\mathrm{CeO}_{2-\mathrm{x}}$ where $\mathrm{x}$ is either $\sim 0.1$ or $\sim 0.25$ [5]. This reduction in the oxidation state of the $\mathrm{CeO}_{2}$ when subjected to reducing processing conditions is analogous to what is expected to happen to ${ }^{238} \mathrm{PuO}_{2}$ and ${ }^{241} \mathrm{AmO}_{\mathrm{x}}$ under similar conditions. However, the magnitude of the reduction is a function of the particular powder composition being processed.

\subsection{NEUTRON RADIATION STUDIES ON RPS THERMOELECTRIC MATERIALS}

Over the years the U.S. has utilized several different thermoelectric materials (including SiGe and TAGS-85) to convert some of the radioisotope decay heat into electrical power. In addition, new thermoelectric materials are currently being investigated for possible application in future RPSs. For example, UD has assisted the U.S. Department of Energy and NASA (Jet Propulsion Laboratory) in studying the effects of neutron irradiation on a potential new generation of skutterudite based RPS thermoelectric materials.

The RPS design being investigated by the University of Leicester would utilize bismuth telluride based thermoelectrics to convert some of the decay heat from the ${ }^{241} \mathrm{AmO}_{\mathrm{x}}$ fuel form into electrical power for a spacecraft. In September 2015, the University of Leicester and the University of Dayton signed an Implementing Arrangement under the auspices of a Memorandum of Understanding between the U.K. Department of Energy and Climate Change and the U.S. Department of Energy. This Arrangement greatly facilities joint space nuclear power related projects to occur between the two universities. Following the signing of the Arrangement, UD and U of L discussed and arranged for neutron irradiation experiments on $\mathrm{U}$ of L supplied BiTe based thermoelectrics. Some of these experiments were performed during November 2015 at a university based reactor facility close to UD in which UD has recently performed similar types of neutron irradiation experiments.

In preparation for the radiation experiments, $\mathrm{U}$ of $\mathrm{L}$ thoroughly characterized various electrical properties of four BiTe thermoelectric modules which were then shipped to UD. Figure 5 shows four U of L supplied thermoelectric modules after being positioned on a test frame prior to the reactor run. The positioning of the modules within the test frame was carefully performed to ensure that all four of the modules were subjected to the same neutron fluence. 


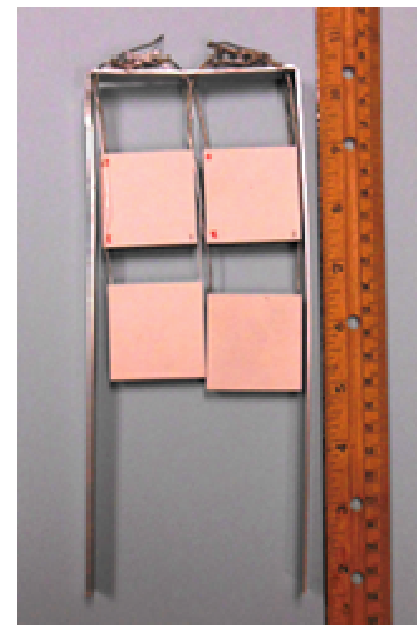

Figure 5. Four bismuth telluride based thermoelectric modules just prior to being loaded into the nuclear reactor.

Figure 6 shows the experimental rig being loaded into a tube located next to the core of the reactor prior to the experimental run. The reactor power used during the neutron radiation experiment was selected to correspond to neutron fluence levels anticipated during a future space mission. After completion of this particular experiment, the thermoelectric modules activated (as expected) and were stored at the reactor facility for a period of time. The modules were later shipped to UD where they were eventually packaged for shipment to $U$ of $\mathrm{L}$ following all international guidelines. $\mathrm{U}$ of $\mathrm{L}$ is currently performing post-performance electrical and other tests on the irradiated modules and these results will be compared to the pre-irradiation test data.

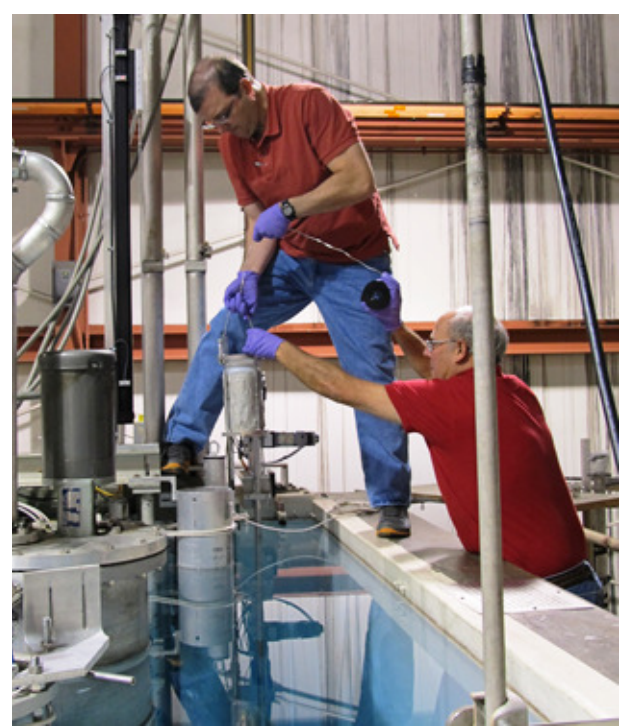

Figure 6. Experimental rig with the four bismuth telleride thermoelectric modules being loaded into the reactor pool.

\section{SUMMARY}

Over the last several years there has been an ongoing technical interchange between the University of Leicester and the National Nuclear Laboratory in the U.K, and the University of Dayton in the U.S. related to various aspects of space radioisotope power systems (RPS). This technical relationship has been mutually beneficial in several materials based technical areas such as the ceramic processing of $\mathrm{CeO}_{2}$ surrogate fuel pellets, and in the study of the effects of neutron radiation on potential RPS materials including thermoelectric modules. It is anticipated that these relationships will continue to develop and grow, which will help to ensure that internationally RPS technology continues to play a major role in deep space exploration of the solar system and beyond.

\section{ACKNOWLEDGEMENTS}

The University of Dayton conducted this research under U.S. Department of Energy/Office of Space \& Defense Power Systems contract No. DE-NE0000422, their continuing support is greatly appreciated.

The University of Leicester and the National Nuclear Laboratory also greatly appreciate the support of the European Space Agency for funding the space nuclear power technology development studies.

\section{REFERENCES}

[1] Pattern: 03-065-5923 $\left(\mathrm{CeO}_{2}\right)$, Inorganic Crystal Structure Database (ICSD), National Institute of Standards and Technology (NIST), Gaithersburg MD.

[2] Pattern: 03-065-7999 $\left(\mathrm{Ce}_{4} \mathrm{O}_{7}\right)$, Inorganic Crystal Structure Database (ICSD), National Institute of Standards and Technology (NIST), Gaithersburg MD.

[3] Pattern: 00-023-1048 $\left(\mathrm{Ce}_{2} \mathrm{O}_{3}\right)$, Inorganic Crystal Structure Database (ICSD), National Institute of Standards and Technology (NIST), Gaithersburg MD.

[4] Bevan, D.J.M., "Ordered Intermediate Phases in the System $\mathrm{CeO}_{2}-\mathrm{Ce}_{2} \mathrm{O}_{3}$," J. Inorganic and Nuclear Chemistry, v. 1, Pergamon Press Ltd., London, UK, page 49-59, 1955.

[5] Kramer, D.P., Pierson, T.M., Sjoblom, C.O., Grant, D.W., Goodrich, S.M., Barlay, C.D., and Whiting, C.E., "Hot Pressing of $\mathrm{CeO}_{2}$ Ceramic Pellets," In Proc. 2015 Nuclear and Emerging Technologies for Space - NETS, Albuquerque, N.M. 